\title{
Review and evaluation of the methodological quality of the existing guidelines and recommendations for inherited neurometabolic disorders
}

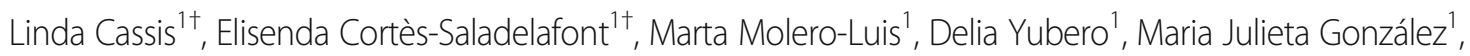
Aida Ormazábal ${ }^{1}$, Carme Fons ${ }^{1}$, Cristina Jou' ${ }^{1}$ Cristina Sierra', Esperanza Castejon Ponce ${ }^{1}$, Federico Ramos ${ }^{1}$, Judith Armstrong ${ }^{1}$, M. Mar O'Callaghan', Mercedes Casado ', Raquel Montero', Silvia Meavilla-Olivas', Rafael Artuch', Ivo Barić ${ }^{2}$, Franco Bartoloni ${ }^{3}$, Cinzia Maria Bellettato ${ }^{4}$, Fedele Bonifazi ${ }^{3}$, Adriana Ceci ${ }^{3}$, Ljerka Cvitanović-Šojat ${ }^{2}$, Christine I Dali ${ }^{5}$, Francesca D'Avanzo ${ }^{4}$, Ksenija Fumic ${ }^{2}$, Viviana Giannuzzi ${ }^{3}$, Christina Lampe ${ }^{4,6}$, Maurizio Scarpa ${ }^{4,6,7}$ and Ángels Garcia-Cazorla ${ }^{1 *}$

\begin{abstract}
Background: Inherited neurometabolic disorders (iNMDs) represent a group of almost seven hundred rare diseases whose common manifestations are clinical neurologic or cognitive symptoms that can appear at any time, in the first months/years of age or even later in adulthood. Early diagnosis and timely treatments are often pivotal for the favorable course of the disease. Thus, the elaboration of new evidence-based recommendations for iNMD diagnosis and management is increasingly requested by health care professionals and patients, even though the methodological quality of existing guidelines is largely unclear. InNerMeD-I-Network is the first European network on iNMDs that was created with the aim of sharing and increasing validated information about diagnosis and management of neurometabolic disorders. One of the goals of the project was to determine the number and the methodological quality of existing guidelines and recommendations for iNMDs.
\end{abstract}

Methods: We performed a systematic search on PubMed, the National Guideline Clearinghouse (NGC), the Guidelines International Network (G-I-N), the Scottish Intercollegiate Guideline Network (SIGN) and the National Institute for Health and Care Excellence (NICE) to identify all the published guidelines and recommendations for iNMDs from January 2000 to June 2015. The methodological quality of the selected documents was determined using the AGREE II instrument, an appraisal tool composed of 6 domains covering 23 key items.

Results: A total of 55 records met the inclusion criteria, $11 \%$ were about groups of disorders, whereas the majority encompassed only one disorder. Lysosomal disorders, and in particular Fabry, Gaucher disease and mucopolysaccharidoses where the most studied. The overall methodological quality of the recommendation was acceptable and increased over time, with $25 \%$ of the identified guidelines strongly recommended by the appraisers, $64 \%$ recommended, and $11 \%$ not recommended. However, heterogeneity in the obtained scores for each domain was observed among documents covering different groups of disorders and some domains like 'stakeholder involvement' and 'applicability' were generally scarcely addressed.

(Continued on next page)

\footnotetext{
* Correspondence: agarcia@hsjdbcn.org

${ }^{\dagger}$ Equal contributors

${ }^{1}$ Neurology, gastroenterology pathology and clinical biochemistry

Departments, IRP-HSJD and CIBERER, Barcelona, Spain

Full list of author information is available at the end of the article
} 
(Continued from previous page)

Conclusions: Greater efforts should be devoted to improve the methodological quality of guidelines and recommendations for iNMDs and AGREE II instrument seems advisable for new guideline development. The elaboration of new guidelines encompassing still uncovered disorders is badly needed.

Keywords: Inherited neurometabolic disorders, Inborn errors of metabolism, Guidelines, Recommendations, AGREE II

\section{Background}

Inherited neurometabolic disorders (iNMDs) comprise almost seven hundred different rare diseases resulting from genetic defects, ranging from abnormal amino acid metabolism, impaired mitochondrial function, abnormal lipid trafficking to lysosomal storage diseases [1, 2]. The genetic defects affecting metabolic enzymes impact on the brain from birth and during the whole developmental period of childhood till adulthood, causing diverse neurological manifestations $[3,4]$.

INMDs, because of their rarity, still represent a challenge for many clinicians who are not able to properly diagnose, treat or follow-up affected patients. In addition, although effective treatments improving the life expectancy and/or quality of life exist for some iNMDs, they are often too expensive, not available in all countries or even administered too late.

Clinical practice guidelines (GLs) are commonly defined as "systematically developed statements to assist practitioner and patient decisions about appropriate health care for specific clinical circumstances" [5]. There are very few GLs and recommendations (RCs) that can assist patients, families, health professionals and support services to correctly manage iNMDs, and their methodological quality has never been systematically evaluated. For this reason, it may be also difficult for practitioners to choose the appropriate recommendations.

Because of the paucity of current information about most of these disorders, the European project "Inherited NeuroMetabolic Disease Information Network" (InNerMeD-I-Network, 201212 12, second Health Programme, http://www.innermed.eu) was launched with the aim of creating a network of information related to diagnosis and treatment of iNMDs. INMDs were classified in ten different categories, starting from previous existing classifications (http://www.orpha.net): (1) disorders of amino acids and organic acids; (2) purine, pyrimidine and neurotrasmitter metabolism diseases (3) disorders of carbohydrate metabolism; (4) disorders of lipid metabolism; (5) disorders of vitamin and non protein cofactor metabolism and transport; (6) disorders of porphyrin and hem metabolism; (7) disorders of mineral absorption and transport; (8) disorders of energy metabolism; (9) disorders of lysosomal and lysosomalrelated organelles and (10) peroxisomal diseases. Recently, a new category of inborn errors of metabolism
(IEMs) that currently includes more than one hundred diseases has been described: the defects of synthesis and remodeling of complex lipids [6].

In the present study we performed a systematic review of the literature to identify all published GLs and RCs about iNMDs. The aim of this study was to evaluate the number and the methodological quality of the GLs and RCs on iNMDs published from 2000 to 2015. To this purpose, we used the Appraisal of Guidelines, Research, and Evaluation II (AGREEII) instrument, a tool that evaluates the rigour and transparency in GL development and how well this process is reported [7-9]. A systematic analysis of the existing GLs and RCs for iNMDs may be useful for new guideline developers willing to follow a structured and rigorous elaboration methodology.

\section{Methods}

\section{Search strategy}

For each of the 682 identified iNMDs, grouped in ten categories, the following electronic databases related to GLs and RCs were systematically searched on FebruaryMarch 2015: PubMed (http://www.ncbi.nlm.nih.gov/ pubmed); the National Guideline Clearinghouse (NGC, http://www.guideline.gov); the Guidelines International Network (G-I-N, http://www.g-i-n.net); the Scottish Intercollegiate Guideline Network (SIGN, http:// www.sign.ac.uk); the National Institute for Health and Care Excellence (NICE, http://www.nice.org.uk). Additional publications were included after manually checking the reference lists of the identified relevant documents. The strategy used to identify the GLs and RCs is shown in Fig. 1.

For PubMed database, the following searching strategy was used for each of the 682 diseases:

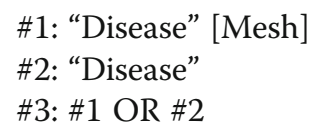

\#4: Recomm* OR Management OR update [TI/AB] OR Therapeutic* [TI/AB] OR treatment* OR guideline* OR consensus OR standard OR criterion [TI/AB])) OR ("Disease Management" [Mesh] OR "Therapeutics" [Mesh] OR "Health Planning Guidelines" [Mesh] OR "Guidelines as Topic" [Mesh] OR "Practice guidelines as Topic" [Mesh] OR "Review" [Publication 


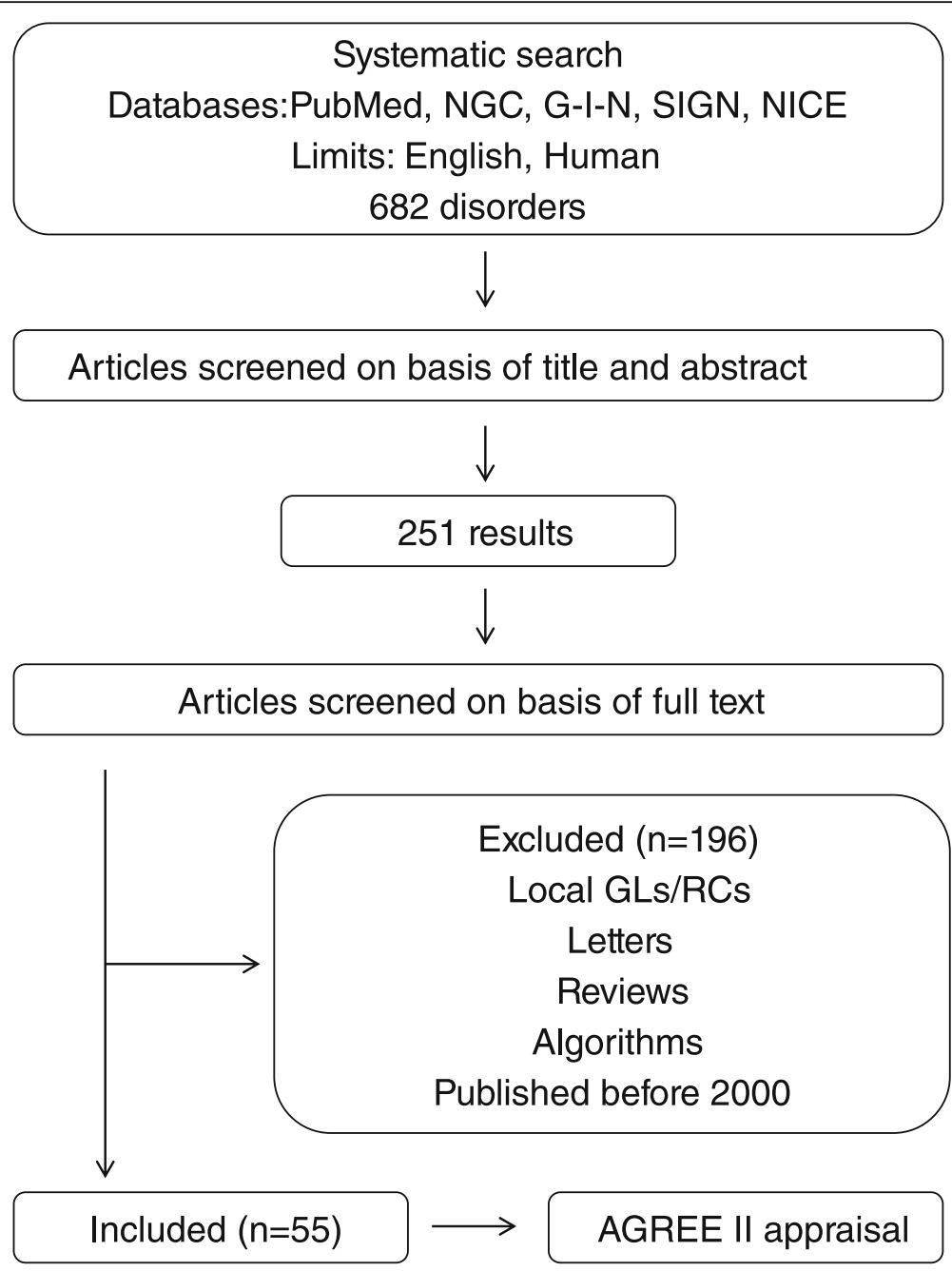

Fig. 1 Flowchart of the strategy used to search and select GLs and RCs. A systematic search of the literature was performed in order to identify GLs and RCs encompassing 682 iNMDs. The documents were firstly selected on the basis of title and abstract (251 items). The analysis of the full text, as well as the application of the exclusion criteria, returned 55 unique documents that underwent AGREE II appraisal. GL: guideline; RC: recommendation; NGC: National Guideline Clearinghouse; G-I-N: Guideline International Network; SIGN: Scottish Intercollegiate Guideline Network; NICE: National Institute for Health and Care Excellence; AGREE: Appraisal of Guidelines, Research, and Evaluation

Type] OR "Guideline" [Publication Type] OR "Practice Guideline" [Publication Type]. \#5: \#3 AND \#4.

Search terms: disease, recommendation, management, update, therapeutic, treatment, guideline, consensus, standard, criterion, disease management, health planning guidelines, practice guideline, review.

\section{Inclusion and exclusion criteria}

All the GLs and RCs published from 2000 to 2015 in the mentioned databases were selected by one of the authors (LC). Only English-written publications were considered. Duplicates of documents, which were found in more than one database, were manually removed from the selection. The initial search yielded unique records based on title and abstract (Fig. 1).

The final documents were then selected by two authors (LC and AGC) after reading the full text. First and updated versions of the same GLs and RCs were considered as distinct documents. Publications were excluded when the method used to formulate the GL or RC did not include a formal consensus process (such as the one reached through the Delphi Method or repetitive encounters) among independent professional groups or individuals. Moreover, GLs and RCs were not considered when they are applicable to one unique country. Reviews, algorithms and letters were also excluded. The selected unique records that responded to all the criteria for evaluation cover disorders related to: 


\begin{tabular}{ll}
\hline A & Amino acid and organic acid metabolism \\
B & Purine, pyrimidine and neurotrasmitter metabolism \\
C & Carbohydrate metabolism \\
D & Lipid metabolism \\
E & Vitamin and non protein cofactor metabolism and transport \\
F & Porphyrin and hem metabolism \\
G & Mineral absorption and transport \\
H & Energy metabolism \\
I & Lysosomal and lysosomal-related organelles \\
J & Peroxisomes \\
\hline
\end{tabular}

Defects of synthesis and remodeling of complex lipids were not considered in the search, because many of them are emerging disorders described in the last recent years.

For each study the following data were extracted: year of publication, name of the covered disease, number of authors, number of countries involved, country of origin of the authors, number of affiliations, and topics (screening, diagnosis, management and follow-up).

\section{Appraisal of guidelines and recommendations}

The AGREE II instrument was used to assess the transparency, the methodological quality and the rigour of the selected GLs and RCs. It consists of 23 key items that address six quality domains: (1) scope and purpose, (2) stakeholder involvement, (3) rigor of development, (4) clarity of presentation, (5) applicability and (6) editorial independence. Two additional items concern the overall judgment of the GL (Overall Guideline Assessment) (Table 1).

The detailed criteria for each item are available in the user manual for AGREE II tool (http://www.agreetrust.org/). Briefly, for each document, the twenty-three items were rated on a 7-point scale (1-strongly disagree to 7-strongly agree) by two trained independent reviewers, experts in the field of IEMs and belonging to clinical, biochemical or genetic professional categories. One reviewer (LC) trained all the reviewers and rated all the documents, in order to provide a minimum variability between appraisals. A score of 1 was given when little or no relevant information was presented and a score of 7 was given when the statement met all criteria. Disagreement between reviewers (defined as $\geq 3$ points difference in the score assigned by the appraisers to the same item) was resolved through consensus. To achieve consensus, the two reviewers shared the rationale for their appraisal and helped by the instructions provided by AGREE II instrument, they reached an agreement. According to AGREE II instructions, domain scores were calculated as (obtained score -minimum possible score)/(maximum possible score - minimum possible score) where "obtained score" is determined by summing up all the scores given by the appraisers for the individual items in a domain. All the final domain scores were entered into an Excel spreadsheet. Since the AGREE II manual does not provide guidance regarding how to interpret scores, to determine the grade of recommendation of the GL/RC we used a method previously applied by other authors with some minor modifications [10].

A GL or RC is "strongly recommended (SR)" when all the six item scores were $\geq 50 \%$ or five item scores were $\geq 50 \%$ and one item score was between 40 and $50 \%$. A guideline is "recommended (R)" if the overall quality assessment (OQA) score was $\geq 50 \%$. A guideline is "not recommended (NR)" if the OQA score was $<50 \%$.

The term GL and RC was assigned to the documents on the basis of the definition that the developers used to define the guidance they elaborated. However, all the articles underwent the same AGREE II appraisal process, regardless if they were GLs or RCs.

\section{Statistics}

Data analysis was performed using the SPSS 22.0 software. The Kolmogorov-Smirnov test was applied to assess the data distribution. The ANOVA test was applied to compare score means of domains and individual questions between the established guideline groups. To study differences between GL groups, either parametric tests (if they follow a Gaussian distribution, Bonferroni Test) or nonparametric test (Games-Hewell) were applied. Pearson correlation test was applied to search for correlation between year of publication and number of GLs or RCs, and overall quality. Finally, the correlation between the quality of a GL and the number of authors, countries and affiliations involved was assessed. Statistical significance was defined as $\mathrm{p}<0.05$.

\section{Results}

A total of 251 unique documents about detection or management of iNMDs are available so far and $87.3 \%$ were published from 2000. The NGC defines GLs as "statements that include recommendations intended to optimize patient care that are informed by a systematic review of evidence and an assessment of the benefits and harms of alternative care options". Following this definition of GL and applying the inclusion and exclusion criteria shown in Fig. 1, only 21.9 \% of the documents analyzed $(n=55)$ corresponded to GLs and RCs eligible for AGREE II appraisal.

\section{Characteristics of the GLs and RCs}

Table 2 summarizes the information relative to the fiftyfive identified GLs and RCs encompassing iNMDs. 
Table 1 AGREE II instrument-domains and items

\begin{tabular}{|c|c|c|}
\hline \multirow[t]{2}{*}{ Domain } & \multicolumn{2}{|l|}{ Item } \\
\hline & Number & Content \\
\hline \multirow[t]{3}{*}{ 1. Scope and purpose } & 1 & The overall objective(s) of the guideline is (are) specifically described \\
\hline & 2 & The clinical question(s) covered by the guideline is (are) specifically described \\
\hline & 3 & The population to whom the guideline is mean to apply is specifically described \\
\hline \multirow[t]{3}{*}{ 2. Stakeholder involvement } & 4 & The guideline development group includes individuals from all relevant professional groups \\
\hline & 5 & The views and preferences of the target population have been sought \\
\hline & 6 & The target users of the guideline are clearly defined \\
\hline \multirow[t]{8}{*}{ 3. Rigour of development } & 7 & Systematic methods were used to search for evidence \\
\hline & 8 & The criteria for selecting the evidence are clearly described \\
\hline & 9 & The strengths and limitations of the body of evidence are clearly described \\
\hline & 10 & The methods for formulating the recommendations are clearly described \\
\hline & 11 & The health benefits, side effects, and risks have been considered in formulating the recommendations \\
\hline & 12 & There is an explicit link between the recommendations and the supporting evidence \\
\hline & 13 & The guideline has been externally reviewed by experts prior to its publication \\
\hline & 14 & A procedure for updating the guideline is provided \\
\hline \multirow[t]{3}{*}{ 4. Clarity of presentation } & 15 & The recommendations are specific and unambiguous \\
\hline & 16 & The different options for management of the condition or health issue are clearly presented \\
\hline & 17 & Key recommendations are easily identifiable \\
\hline \multirow[t]{4}{*}{ 5. Applicability } & 18 & The guideline describes facilitators and barriers to its application \\
\hline & 19 & The guideline provides advice and/or tools on how the recommendations can be put into practice \\
\hline & 20 & The potential resource implications of applying the recommendations have been considered \\
\hline & 21 & The guideline presents monitoring and/or auditing criteria \\
\hline \multirow[t]{2}{*}{ 6. Editorial independence } & 22 & The views of the funding body have not influenced the content of the guideline \\
\hline & 23 & Competing interests of guideline development group members have been recorded and addressed \\
\hline \multirow[t]{2}{*}{ Overall assessment } & 1 & Overall quality of this guideline \\
\hline & 2 & Would you recommend this guideline for use? \\
\hline
\end{tabular}

GLs and RCs were identified for almost all the subtypes of iNMDs, except for disorders of purine, pyrimidine and other neurotransmitter metabolism (group B), lipid metabolism (group D) and peroxisomal disorders (group J). The groups of disorders highly differed in the number of associated GLs and RCs, since documents encompassing disorders of vitamin and non protein cofactor metabolism and transport (group E), porphirin and hem metabolism (group F) and energy metabolism (group $\mathrm{H}$ ) were covered by a small number of GLs and RCs $(n=2, n=1, n=3$, respectively). In contrast, the disorders associated with lysosomal and lysosomalrelated organelles were the most encompassed by GLs and RCs $(n=27$, Fig. 2a). These numbers did not necessarily correlate with the number of disorders in each group. For instance, the number of disorders associated to lysosome and lysosomal-related organelles (group I, $n=115$ ) was lower than the number of disorders of energy metabolism (group $\mathrm{H}, n=155$ ), even though the number of GLs and RCs was ninefold higher in the former group $(n=27$ and $n=3$, respectively, Fig. 2b).

Six of the identified documents were about groups of disorders (11\%), while the remaining 49 pubblications focused on one unique disorder and globally covered twenty different diseases (Table 2). Moreover, $52 \%$ of the considered pathological conditions were covered by only one document. In contrast, GLs and RCs about Gaucher disease, Fabry disease, and mucopolysaccharidoses (MPSs) were reported in seven (Gaucher disease) and eight (Fabry disease and MPSs) different publications (Additional file 1: Table S1 and Fig. 2c).

Although the number of new documents/year has been quite stable all over the last first decade, the overall frequency of GLs and RCs about iNMDs has significantly increased over time (Fig. $3 a$ and b).

The analysis of the country of origin of the authors revealed that $29.1 \%$ of the GLs and RCs were from Europe, 23.6 \% from USA and the remaining $42.3 \%$ 
Table 2 Characteristics of the guidelines and recommendations

\begin{tabular}{|c|c|c|c|c|c|c|}
\hline Authors/titles & Year & Disorder & Authors (n) & Countries (n) & Affiliations (n) & Topics \\
\hline \multicolumn{7}{|c|}{ Disorders of amino acid and other organic acid metabolism } \\
\hline Arnold GL [22] & 2008 & 3-methylcrotonyl CoA carboxylase deficiency & 15 & 2 & 15 & Diagnosis, management \\
\hline Baumgartner MR [37] & 2014 & Methylmalonic and propionic acidemia & 25 & 12 & 21 & $\begin{array}{l}\text { Screening, diagnosis, } \\
\text { management, follow-up }\end{array}$ \\
\hline Frazier D [38] & 2014 & Maple syrup urine disease & 9 & 1 & 9 & Management \\
\hline Haberle J [19] & 2012 & Urea cycle disorders & 15 & 4 & 14 & $\begin{array}{l}\text { Screening, diagnosis, } \\
\text { management, follow-up }\end{array}$ \\
\hline Kölker S [20] & 2011 & Glutaric aciduria type I & 19 & 8 & 15 & $\begin{array}{l}\text { Screening, diagnosis, } \\
\text { management }\end{array}$ \\
\hline Kölker S [39] & 2007 & Glutaric aciduria type I & 19 & 10 & 15 & $\begin{array}{l}\text { Screening, diagnosis, } \\
\text { management }\end{array}$ \\
\hline $\mathrm{NIH}$ CDP [40] & 2001 & Phenylketonuria & 14 & 1 & 14 & $\begin{array}{l}\text { Screening, diagnosis, } \\
\text { management, follow-up }\end{array}$ \\
\hline Vockley J [41] & 2014 & Phenylketonuria & 10 & 1 & 10 & $\begin{array}{l}\text { Screening, diagnosis, } \\
\text { management, follow-up }\end{array}$ \\
\hline \multicolumn{7}{|c|}{ Disorders of carbohydrate metabolism } \\
\hline Barba-Romero MA [42] & 2012 & Pompe disease & 13 & 1 & 13 & $\begin{array}{l}\text { Diagnosis, management, } \\
\text { follow-up }\end{array}$ \\
\hline Cochat P [43] & 2012 & Primary hyperoxaluria Type 1 & 18 & 6 & 16 & $\begin{array}{l}\text { Screening, diagnosis, } \\
\text { management }\end{array}$ \\
\hline Cupler EJ [44] & 2012 & Pompe disease & 7 & 1 & 7 & Diagnosis, management \\
\hline Kishnani PS [45] & 2014 & Glycogen storage disease type I & 15 & 1 & 8 & Diagnosis, management \\
\hline Kishnani PS [46] & 2010 & Glycogen Storage Disease Type III & 16 & 1 & 10 & $\begin{array}{l}\text { Screening, diagnosis, } \\
\text { management }\end{array}$ \\
\hline Kishnani PS [47] & 2006 & Pompe disease & 22 & 3 & 15 & $\begin{array}{l}\text { Screening, diagnosis, } \\
\text { management, follow-up }\end{array}$ \\
\hline Rake JP [48] & 2002 & Glycogen storage disease type I & 6 & 4 & 4 & $\begin{array}{l}\text { Diagnosis, management, } \\
\text { follow-up }\end{array}$ \\
\hline Visser G [49] & 2002 & Glycogen Stoage Disease type I & 8 & 5 & 6 & Management \\
\hline Winchester B [50] & 2008 & Pompe disease & 29 & 17 & 25 & Diagnosis \\
\hline \multicolumn{7}{|c|}{ Disorders of vitamin and non protein cofactor metabolism and transport } \\
\hline BCMSC [51] & 2011 & Cobalamin deciciency & unclear & 1 & unclear & $\begin{array}{l}\text { Diagnosis, management, } \\
\text { follow-up }\end{array}$ \\
\hline Devalia V [52] & 2014 & Cobalamin and folate disorders & 3 & 2 & 3 & $\begin{array}{l}\text { Screening, diagnosis, } \\
\text { management }\end{array}$ \\
\hline \multicolumn{7}{|c|}{ Disorders of porphyrin and haem metabolism } \\
\hline Stein P [53] & 2013 & Porphyria & 5 & 1 & 5 & Diagnosis, management \\
\hline \multicolumn{7}{|c|}{ Disorders of mineral absorption and transport } \\
\hline Bacon BR [54] & 2011 & Hemochromatosis & 5 & 2 & 5 & $\begin{array}{l}\text { Screening, diagnosis, } \\
\text { management }\end{array}$ \\
\hline BCMA [55] & 2013 & Hemochromatosis & Unclear & 1 & Unclear & $\begin{array}{l}\text { Screening, diagnosis, } \\
\text { management }\end{array}$ \\
\hline EASL [56] & 2012 & Wilson Disease & 8 & Unclear & Unclear & $\begin{array}{l}\text { Screening, diagnosis, } \\
\text { management }\end{array}$ \\
\hline Qaseem A [57] & 2005 & Hemochromatosis & 6 & 1 & 5 & Screening \\
\hline Roberts EA [58] & 2003 & Wilson Disease & 2 & 2 & 2 & Diagnosis, management \\
\hline \multicolumn{7}{|c|}{ Disorders of energy metabolism } \\
\hline Angelini [23] & 2006 & Fatty acid mitochondrial disorders & 6 & 4 & 5 & Diagnosis, management \\
\hline Arnold GL [59] & 2009 & Very long chain acyl-CoA dehydrogenase & 14 & 2 & 14 & Diagnosis, management \\
\hline
\end{tabular}


Table 2 Characteristics of the guidelines and recommendations (Continued)

\begin{tabular}{|c|c|c|c|c|c|c|}
\hline Finsterer J [60] & 2009 & Mitochondrial disorders & 18 & 12 & 18 & Diagnosis \\
\hline \multicolumn{7}{|c|}{ Disorders of lysosomal and lysosomal-related organelles } \\
\hline Andersson [61] & 2005 & Gaucher disease & 10 & 1 & 10 & Management, follow-up \\
\hline Bennett RL [62] & 2002 & Fabry disease & 9 & 1 & 8 & $\begin{array}{l}\text { Diagnosis, management, } \\
\text { follow-up }\end{array}$ \\
\hline Biegstraaten M [63] & 2015 & Fabry disease & 34 & 15 & 29 & Management \\
\hline Charrow J [64] & 2004 & Gaucher disease & 11 & 1 & 10 & $\begin{array}{l}\text { Diagnosis, management, } \\
\text { follow-up }\end{array}$ \\
\hline de $\mathrm{Ru} \mathrm{MH}[65]$ & 2011 & Mucopolysaccharidosis type I & 16 & 6 & 14 & Management \\
\hline Desnick RJ [66] & 2003 & Fabry disease & 9 & 2 & 9 & $\begin{array}{l}\text { Diagnosis, management, } \\
\text { follow-up }\end{array}$ \\
\hline Eng CM [67] & 2006 & Fabry disease & 13 & 4 & 11 & $\begin{array}{l}\text { Diagnosis, management, } \\
\text { follow-up }\end{array}$ \\
\hline Fahnehjelm KT [68] & 2012 & Mucopolysaccharidosis & 7 & 5 & 5 & Diagnosis, management \\
\hline Giugliani R [69] & 2007 & Mucopolysaccharidosis VI & 3 & 3 & 3 & $\begin{array}{l}\text { Diagnosis, management, } \\
\text { follow-up }\end{array}$ \\
\hline Grabowski GA [70] & 2004 & Gaucher disease & 11 & 5 & 10 & Diagnosis, management \\
\hline Kaplan P [24] & 2013 & Gaucher disease & 11 & 9 & 11 & $\begin{array}{l}\text { Diagnosis, management, } \\
\text { follow-up }\end{array}$ \\
\hline Kes VB [71] & 2013 & Fabry disease & 16 & 1 & 11 & $\begin{array}{l}\text { Screening, diagnosis, } \\
\text { management, follow-up }\end{array}$ \\
\hline Laney DA [72] & 2013 & Fabry disease & 9 & 1 & 9 & $\begin{array}{l}\text { Screening, diagnosis, } \\
\text { management, follow-up }\end{array}$ \\
\hline Langereis EJ [36] & 2013 & Mucopolysaccharidosis type I & 17 & 8 & 15 & $\begin{array}{l}\text { Diagnosis, management, } \\
\text { follow-up }\end{array}$ \\
\hline Muenzer J [35] & 2012 & Mucopolysaccharidosis type II & 11 & 6 & 11 & Management, follow-up \\
\hline Muenzer J [73] & 2009 & Mucopolysaccharidosis type I & 12 & 6 & Unclear & $\begin{array}{l}\text { Diagnosis, management, } \\
\text { follow-up }\end{array}$ \\
\hline Ortiz A [74] & 2008 & Fabry disease & 6 & 5 & 6 & $\begin{array}{l}\text { Diagnosis, management, } \\
\text { follow-up }\end{array}$ \\
\hline Patterson MC [25] & 2012 & Niemann-Pick disease type $C$ & 6 & 5 & 6 & $\begin{array}{l}\text { Diagnosis, management, } \\
\text { follow-up }\end{array}$ \\
\hline Peters C [75] & 2003 & Hematopoietic cell transplantation for IMDs & Unclear & Unclear & 2 & Management, follow-up \\
\hline Scarpa M [34] & 2011 & Mucopolysaccharidosis type II & 26 & 14 & 25 & $\begin{array}{l}\text { Screening, diagnosis, } \\
\text { management }\end{array}$ \\
\hline Solanki GA [76] & 2012 & Mucopolysaccharidosis type VI & 13 & 4 & 13 & $\begin{array}{l}\text { Diagnosis, management, } \\
\text { follow-up }\end{array}$ \\
\hline Terryn W [77] & 2013 & Fabry disease & 9 & 5 & 9 & $\begin{array}{l}\text { Screening, diagnosis, } \\
\text { management, follow-up }\end{array}$ \\
\hline Vellodi A [78] & 2001 & Gaucher disease & 8 & 6 & 8 & Maganement, follow-up \\
\hline Vom Dahl S [79] & 2006 & Gaucher disease & 7 & 4 & 7 & Follow-up \\
\hline Wang RY [80] & 2011 & Lysosomal storage diseases & 4 & 1 & 5 & $\begin{array}{l}\text { Screening, diagnosis, } \\
\text { management, follow-up }\end{array}$ \\
\hline Weinreb NJ [26] & 2004 & Gaucher disease & 25 & 14 & 24 & Diagnosis, follow-up \\
\hline Wraith JE [81] & 2009 & Niemann-Pick disease type $C$ & 13 & 10 & 13 & $\begin{array}{l}\text { Screening, diagnosis, } \\
\text { management, follow-up }\end{array}$ \\
\hline
\end{tabular}

NIH CDP National institutes of health consensus development panel, BCMSC British Columbia medical services Commission, $B C M A$ British Columbia medical association, EASL European association for study of liver

documents were the result of a collaboration among authors coming from different continents or American countries (miscellanueous origin) (Fig. 3c).
Finally, $87.3 \%$ of the GLs and RCs covered more than one topic and dealt principally with the diagnosis $(80 \%)$ and management $(91 \%)$ of the disease. Screening and 

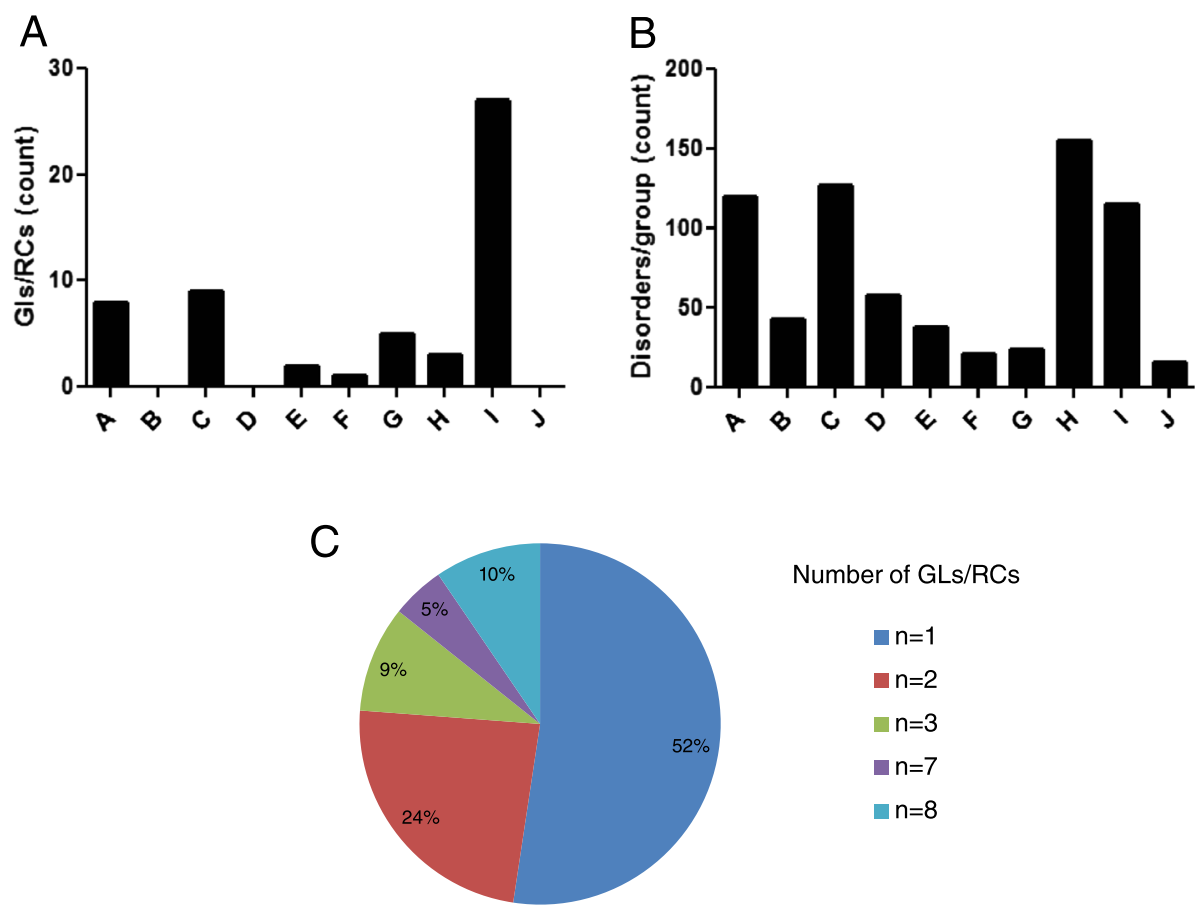

Fig. 2 Characteristics of the identified GLs and RCs. a Number of the GLs and RCs selected for each group of disorders. $\mathbf{b}$ Number of disorders belonging to each group. c Percentage of disorders for which 1 to 8 different GLs and RCs were identified. A: amino acid and organic acid metabolism ( $n=8)$; B: Purine, pyrimidine and neurotrasmitter metabolism ( $n=0)$; C: carbohydrate metabolism $(n=9)$; D: lipid metabolism $(n=0)$; E: vitamin and non protein cofactor metabolism and transport $(n=2)$; F: porphyrin and hem metabolism $(n=1)$; G: mineral absorption and transport $(n=5)$; H: energy metabolism $(n=3)$; I: lysosomal and lysosomal-related organelles $(n=27)$; J: peroxisomes $(n=0)$

follow-up-related issues were encompassed by $34 \%$ and $55 \%$ of the documents, respectively. No GLs and RCs have been developed for the follow-up of disorders of porphirin and hem metabolism (group F), mineral absorption and transport (group G) and energy metabolism (group H, Table 2 and Fig. 3d).

The level of recommendation of the GLs and RCs was determined by the number of items scoring $\geq 50 \%$. The AGREE II analysis revealed that $25 \%$ of the identified GLs were strongly recommended (SR), $64 \%$ recommended (R), and $11 \%$ not recommended (NR, Fig. 4a). All the documents had at least one item scoring $\geq 50 \%$ (Table 3). We excluded from the subsequent statistical analysis the unique document relative to disorders of porphirin and hem metabolism (group F).

\section{Overall quality assessment of GLs and RCs}

In this domain, the appraiser is invited to judge the overall quality of the GL and to indicate whether she/he would recommend it for use.

The range and mean \pm SD of the overall quality assessment (OQA) score for this domain were 25-92\% and $63 \% \pm 15 \%$ (Table 3 and Fig. 4b). Interestingly, although we did not find any statistically significant differences among groups, the OQA of the GLs and RCs about iNMDs increased over the years (Fig. 4c).
A further 3-point scale $(1=$ not recommended, NR; $2=$ recommended with modifications, $R+M$, and $3=$ recommended, $\mathrm{R}$ ) was introduced in the analysis, providing an additional overall judgment on whether the GLs or RCs should be recommended for use (Table 3). For this item, the range and mean $\pm \mathrm{SD}$ of the overall score were $1.5-3 \%$ and $2.2 \% \pm 0.4 \%$. Almost all the GLs and RCs were recommended, since they scored $\geq 2$, except for six documents (11 \%) that were not recommended. On the other hand, appraisers considered that $83 \%$ of the GLs and RCs required modifications. Of note, two out of three documents recommended without modifications by both appraisers belonged to the group of amino acid and organic acid metabolism (group A).

The quality of a GL is supposed to improve when it is developed by experienced experts coming from different countries, or distinct professional categories. For this reason, we next wondered whether the overall quality of the GLs and RCs could depend on the number of authors, countries or affiliations to which authors belong. Figure 5a-c shows that a direct correlation between the OQA and these parameters could not be determined, although a non statistically significant increase in the OQA was observed for higher number of authors and affiliations. 


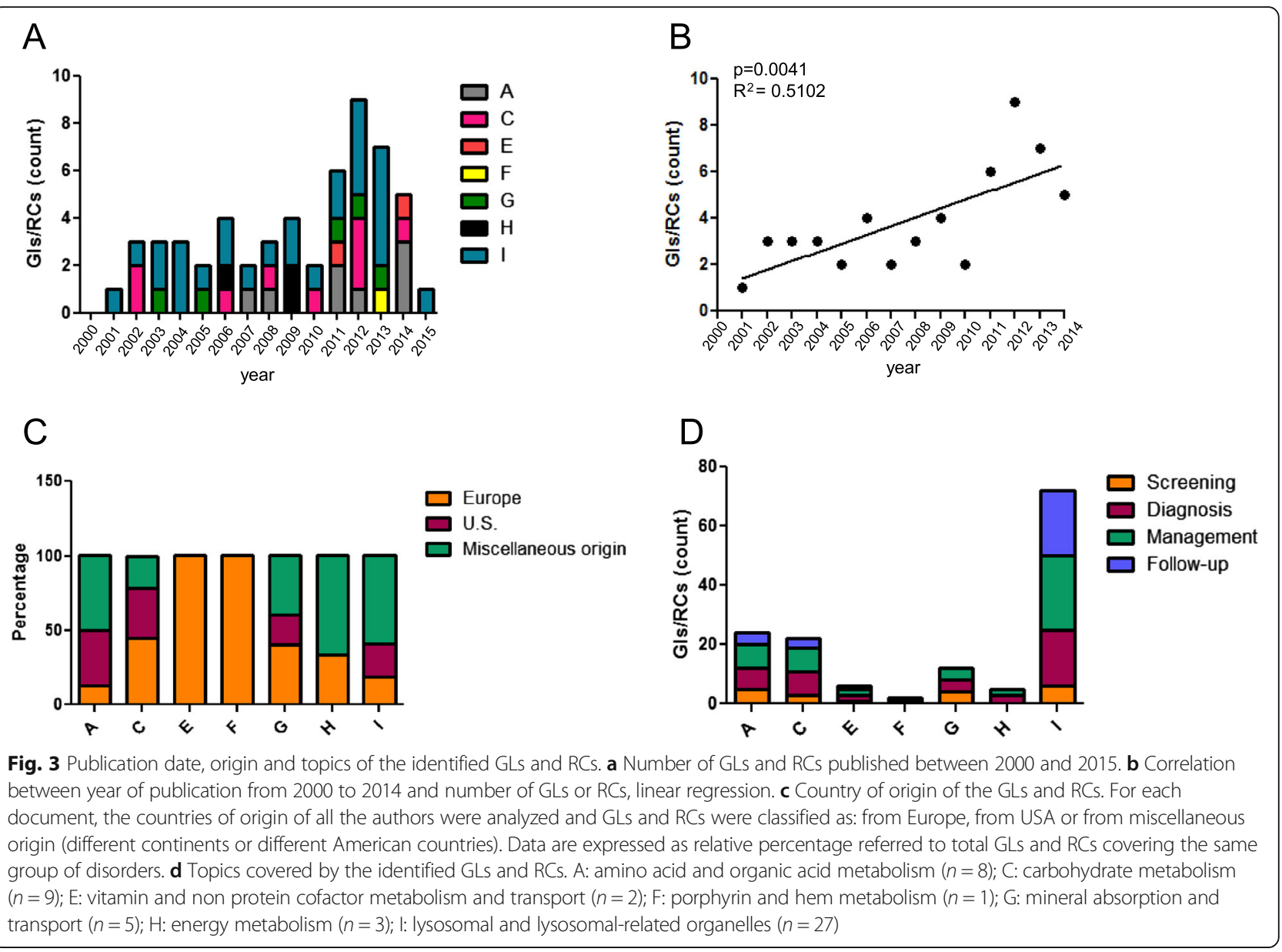

\section{Domain 1: scope and purpose}

This domain considers whether the overall objectives of the GL, the health questions covered by the GL and the population whom the GL is directed to are specifically described. The range and mean \pm SD of the overall score for this domain were $56-100 \%$ and $78 \% \pm 18 \%$. Table 3 and Fig. 6a report the score recorded for each GL and the overall score obtained by the different groups of disorders. The scores were comparable for all the considered groups. None of the GLs or RCs scored $<50 \%$.

\section{Domain 2: stakeholder involvement}

This domain evaluates whether the GL development group includes individuals from all relevant professional groups, the views and preferences of the target population have been sought, and the target users of the GL are clearly defined. The range and mean $\pm \mathrm{SD}$ of the overall score for this domain were $8-92 \%$ and $48 \% \pm$ $23 \%$ (Table 3 and Fig. 6b). Almost half of the overall GLs and RCs, as well as all the documents related to disorders of vitamin and non protein cofactor metabolism and transport (group E) and mineral absorption and transport (group G), scored $<50 \%$. In addition, we also found statistically significant differences in the scores obtained by the different groups in item 4 , which refers to the composition of the GL development group (Fig. 7a). For item 5, referring to the involvement of the target population in the elaboration of the GLs, $75 \%$ of the documents had a score between 1 and 2, indicating that most of them did not consider patients or public in the process (data not shown).

\section{Domain 3: rigour of development}

This domain relates to the method used to search and select the evidence and to formulate the GL. It also focuses on the health benefits, side effects, and risks that should be considered when formulating the recommendations. The range and mean $\pm \mathrm{SD}$ of the overall score for this domain were $13-95 \%$ and $48 \% \pm 22 \%$. (Table 3 and Fig. 6c).

Whereas all the documents for disorders of amino acid and organic acid metabolism (group A) obtained a mean score $\geq 50 \%$, thirty-one GLs and RCs (56\%) presented scores $<50 \%$ for this domain.

The statistical analysis of the distinct items revealed that the seven groups of disorders obtained different 

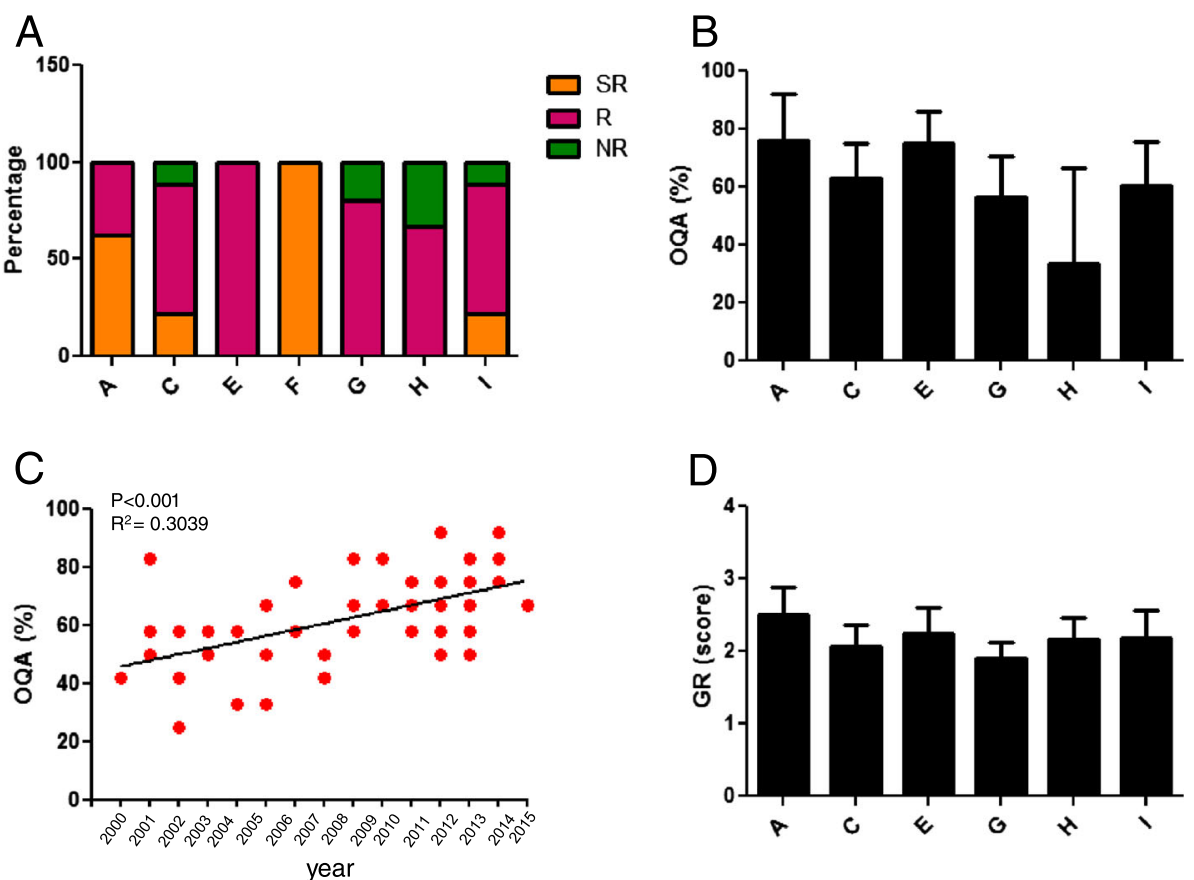

Fig. 4 Overall quality of the identified GLs and RCs. a Overall recommendation: percentage of strongly recommended (SR), recommended (R) and not recommended (NR) GLs and RCs. Data are expressed as relative percentage referred to total GLs and RCs covering the same group of diseases. $\mathbf{b}$ Overall quality assessment (OQA) of GLs and RCs. Data are presented as mean \pm SD. c Correlation between OQA and year of publication, linear regression. $\mathbf{d}$ Grade of recommendation (GR) of GLs and RCs (scores from 1 = not recommended to $3=$ recommended without modifications). Data are presented as mean \pm SD. A: amino acid and organic acid metabolism $(n=8)$; C: carbohydrate metabolism $(n=9)$; D: lipid metabolism; E: vitamin and non protein cofactor metabolism and transport; G: mineral absorption and transport $(n=5)$; H: energy metabolism $(n=3)$; I: lysosomal and lysosomal-related organelles $(n=27)$

scores in items 7, 8, 9, 10 and 13 (Fig. 7b-f). Item 13 considers whether the GL has been externally reviewed by experts prior to its publication. For this items, only $30 \%$ of the documents obtained a score $>3$, indicating that the majority did not undergo an external revision prior to submission for publication or did not provide sufficient information. Item 14 judges if a procedure for GL updating has been established and $73 \%$ of the documents provided scarce information (score $\leq 3$, data not shown).

\section{Domain 4: clarity of presentation}

This domain examines whether the RCs are specific and unambiguous, the different options for management are clearly presented and key RCs are easily identifiable. The range and mean $\pm \mathrm{SD}$ of the overall score for this domain were $31-100 \%$ and $74 \% \pm$ $20 \%$. Table 3 and Fig. $6 \mathrm{~d}$ show that all the groups of disorders presented a comparable score for this domain and no statistically significant difference was observed. Only two documents (3.6\%), belonging to the disorders of energy metabolism (group $\mathrm{H}$ ) and lysosomal and lysosomal-related organelles (group I), presented scores $<50 \%$.

\section{Domain 5: applicability}

This domain examines whether the GL describes facilitators and barriers to its application, explains how the RCs could be put into practice and considers the potential resource implications of applying the RCs. The range and mean \pm SD of the overall score for this domain were $8-73 \%$ and $39 \% \pm 16 \%$ (Table 3 and Fig. 6e). Collectively, $76 \%$ of all the identified documents had a score $<50 \%$ and all the GLs and RCs about mineral absorption and transport (group G) and energy metabolism (group $\mathrm{H}$ ) obtained scores $<50 \%$. Analyzing the distinct items, we observed that $38,58,80$ and $24 \%$ of the documents achieved scores $\leq 3$ for item $18,19,20$, and 21 , respectively. In particular, for item 20 (potential cost impact of the GL) the majority of the identified GLs did not sufficiently consider the cost effectiveness or implications for budget of applying the recommendations (data not shown).

\section{Domain 6: editorial independence}

This domain assesses whether the views of the funding body have not influenced the content of the GL and whether the competing interests of GL development group members have been recorded and addressed. The range and mean $\pm S D$ of the overall score for this 
Cassis et al. Orphanet Journal of Rare Diseases (2015) 10:164

Page 11 of 19

Table 3 Results of AGREE II appraisal for all the identified guidelines and recommendations

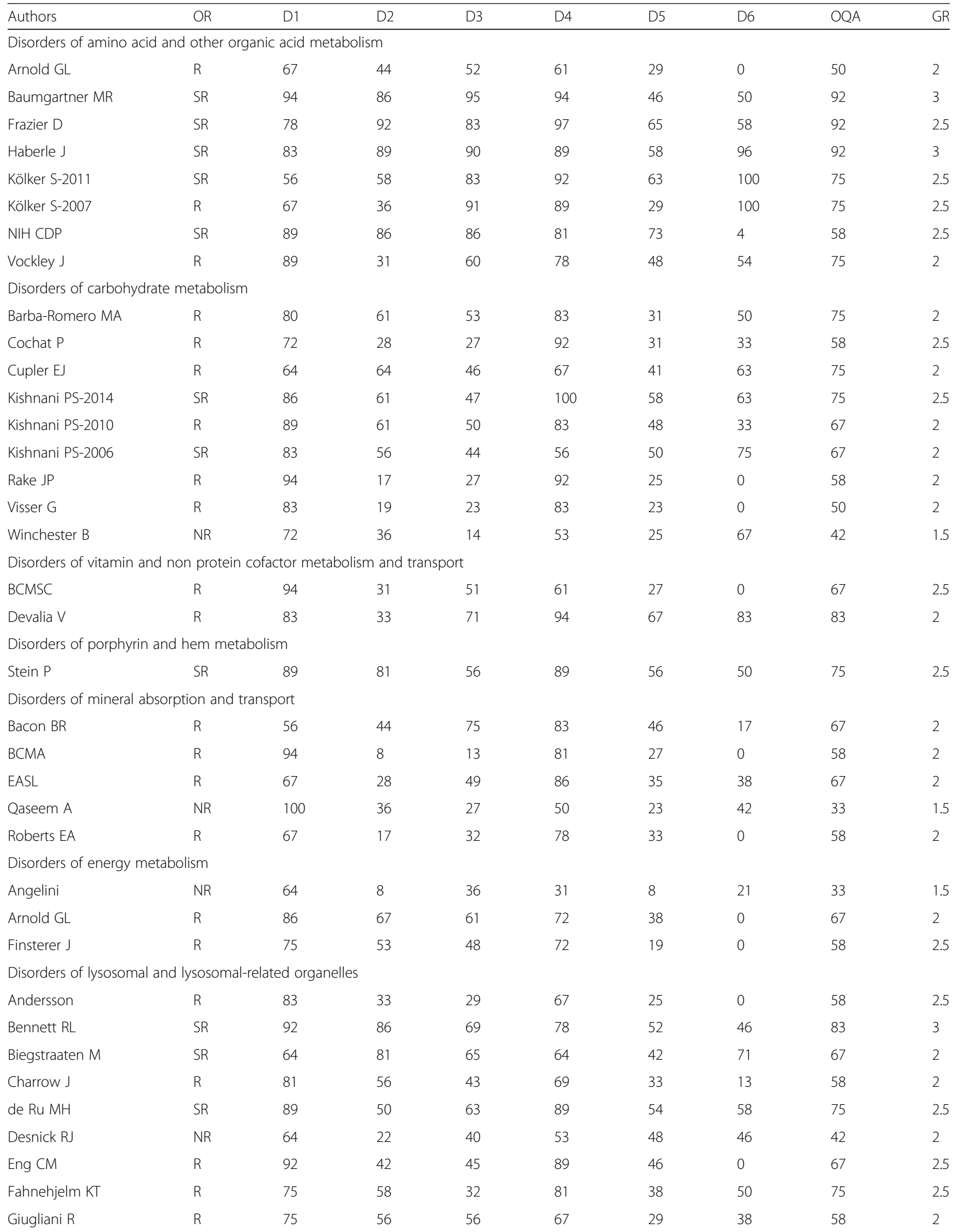


Table 3 Results of AGREE II appraisal for all the identified guidelines and recommendations (Continued)

\begin{tabular}{|c|c|c|c|c|c|c|c|c|c|}
\hline Grabowski GA & $\mathrm{R}$ & 72 & 33 & 27 & 56 & 33 & 0 & 50 & 2 \\
\hline Kaplan P & $\mathrm{R}$ & 78 & 39 & 29 & 78 & 38 & 100 & 83 & 2 \\
\hline Kes VB & $\mathrm{R}$ & 61 & 33 & 29 & 56 & 21 & 0 & 50 & 2 \\
\hline Laney DA & $\mathrm{R}$ & 94 & 92 & 46 & 78 & 46 & 83 & 67 & 2.5 \\
\hline Langereis EJ & $\mathrm{R}$ & 86 & 72 & 58 & 53 & 23 & 46 & 58 & 2 \\
\hline Muenzer J-2012 & $\mathrm{R}$ & 92 & 53 & 33 & 69 & 40 & 92 & 50 & 2.5 \\
\hline Muenzer J-2009 & $\mathrm{R}$ & 69 & 36 & 28 & 69 & 42 & 50 & 58 & 2 \\
\hline Ortiz A & $\mathrm{R}$ & 58 & 31 & 40 & 61 & 23 & 92 & 50 & 2.5 \\
\hline Patterson MC & $\mathrm{R}$ & 78 & 28 & 38 & 78 & 42 & 4 & 67 & 2 \\
\hline Peters C & NR & 64 & 39 & 25 & 33 & 13 & 0 & 25 & 1.5 \\
\hline Scarpa M & $S R$ & 61 & 75 & 61 & 89 & 42 & 58 & 75 & 2.5 \\
\hline Solanki GA & $\mathrm{R}$ & 72 & 39 & 24 & 61 & 54 & 100 & 50 & 1.5 \\
\hline Terryn W & $S R$ & 81 & 44 & 67 & 78 & 58 & 54 & 67 & 2.5 \\
\hline Vellodi A & NR & 83 & 61 & 30 & 72 & 17 & 0 & 42 & 1.5 \\
\hline Vom Dahl S & $\mathrm{R}$ & 89 & 36 & 54 & 56 & 31 & 83 & 50 & 2 \\
\hline Wang RY & $S R$ & 92 & 64 & 53 & 92 & 67 & 92 & 83 & 2.5 \\
\hline Weinreb NJ & $\mathrm{R}$ & 67 & 39 & 30 & 67 & 17 & 4 & 50 & 2 \\
\hline Wraith JE & $\mathrm{R}$ & 83 & 28 & 46 & 83 & 42 & 0 & 83 & 3 \\
\hline
\end{tabular}

OR Overall recommendation, D Domain, OQA Overall quality assessment, GR Grade of recommendation, NIH CDP National institutes of health consensus development panel, $B C M S C$ British Columbia medical services commission, BCMA British Columbia medical association, EASL European association for study of liver, SR Strongly recommended, $R$ Recommended, $N R$ Not recommended domain scores were calculated as described in Methods
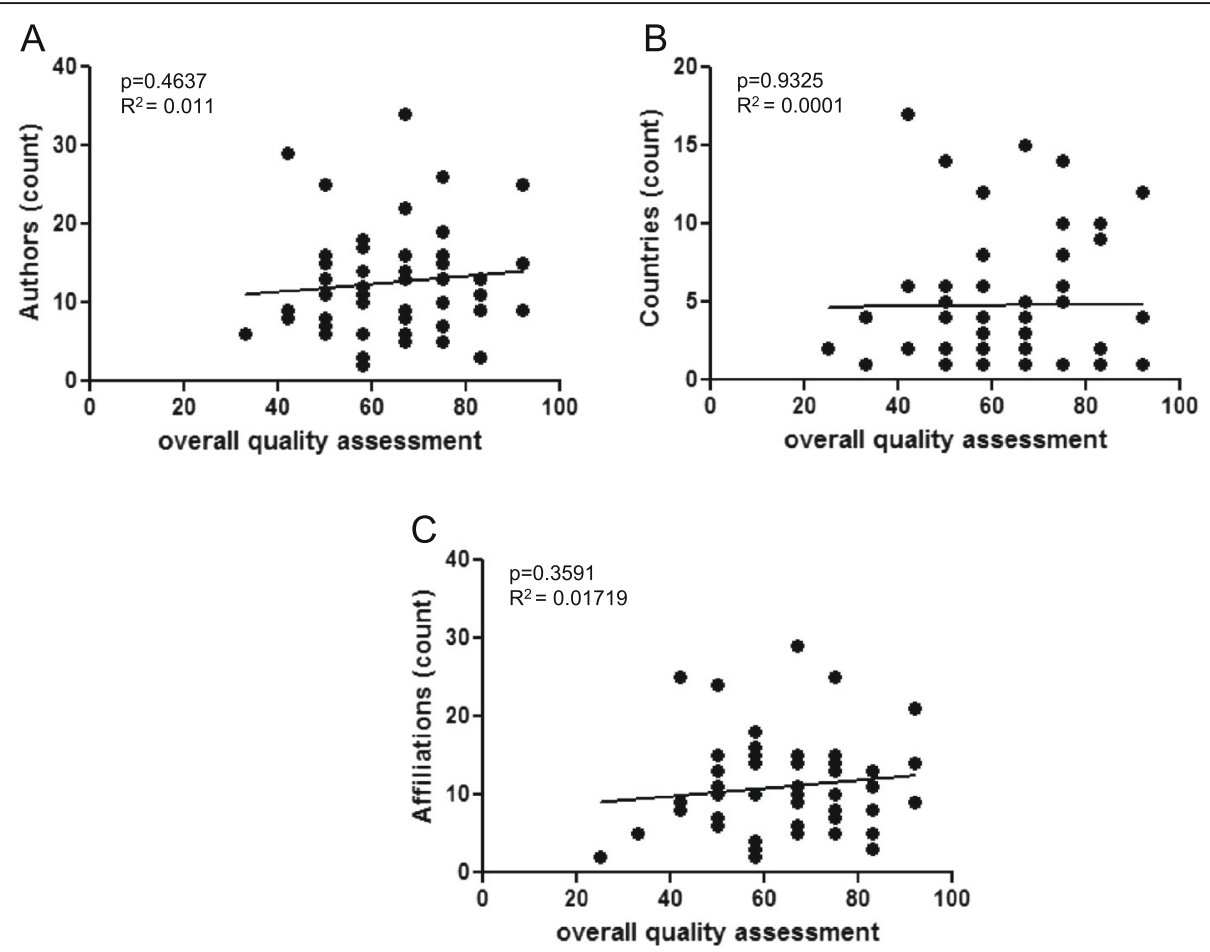

Fig. 5 Correlation between quality of the GLs/RCs and number of authors, countries or affiliations. Linear regression analysis was used to determine whether the overall quality assessment (OQA) of a GL could depend on the number of authors (a), countries (b) or affiliations (c) involved in its elaboration 


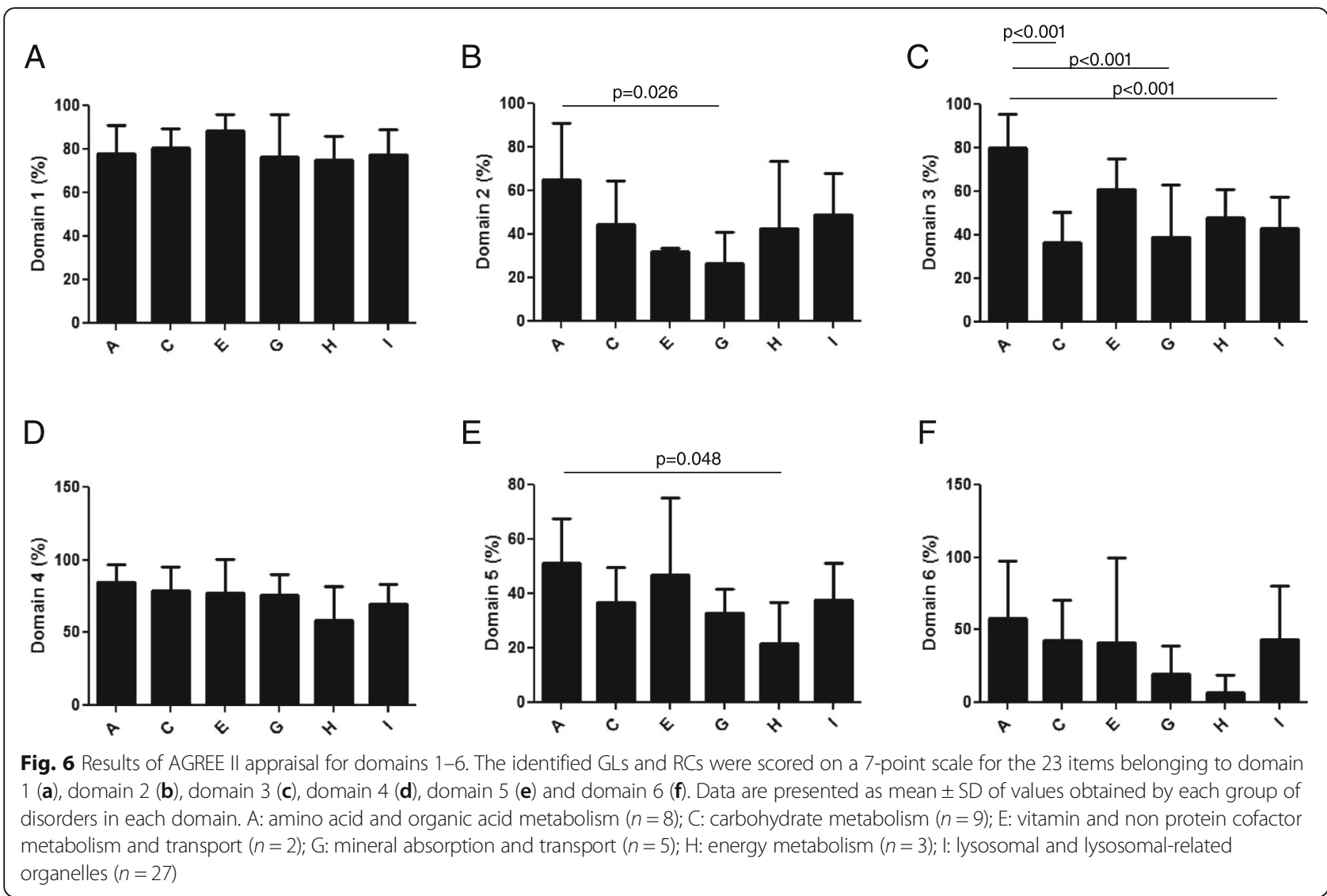

domain were $0-100 \%$ and $41 \% \pm 35 \%$. (Table 3 and Fig. 6f). No statistically significant difference was observed among groups. Only $47 \%$ of total GLs and RCs had a score $\geq 50 \%$ and none of the documents related to disorders of energy metabolism (group $\mathrm{H}$ ) and mineral absorption and transport (group G) reached this score for this domain.

\section{Gaucher disease and Fabry disease were the most studied diseases}

We next focused on two lysosomal storage disorders, Gaucher disease and Fabry disease, encompassed by seven and eight different GLs and RCs, respectively. Gaucher disease is an inherited disorder with an estimated birth prevalence of 1:40,000 to $1: 60,000$, caused by deficient activity of the lysosomal enzyme glucocerebrosidase [11, 12]. Fabry disease affects approximately 1:40,000-170,000 individuals and it is caused by a deficiency of the lysosomal hydrolase $\alpha$ - galactosidase A [13].

The aim was to determine whether the quality and rigour of the GLs and RCs improved over time. For this purpose, the scores referring to domains $1-6$ and to the OQA domain were analyzed. For Gaucher disease, we did not find an increase in the scores referring to domains 1-6. However, a statistically significant increase in the OQA was observed (Additional file 1: Table S1 and Fig. $8 \mathrm{a}$ and $\mathrm{b})$.

By contrast, for Fabry disease no improvement was observed in none of the appraised domains (Fig. 8c and d).

\section{Discussion}

This is the first systematic estimation of the number and methodological quality of all existing GLs and RCs about iNMDs, which have been reclassified inside the activities of the EU funded project InNerMeD-I- Network. The project InNerMeD-I-Network is aimed to group the most vast multidisciplinary network in order to collect, exchange and share validated information among scientific communities, health professionals, patients, patient associations, public health authorities, pharmaceutical companies and other interested parties. One of the focus of this project is the analysis of existing and the elaboration of new GLs and RCs that will provide practical support for the diagnosis and treatment of iNMDs.

To this aim, for the analysis of existing GLs and RCs for iNMDs, we have selected the AGREE II instrument, considered one of the best choice to conduct a comprehensive GL appraisal [7, 14]. Importantly, AGREE II tool does not evaluate the medical/scientific content validity or the evidence base underlying a $\mathrm{RC}$, but the rigour 

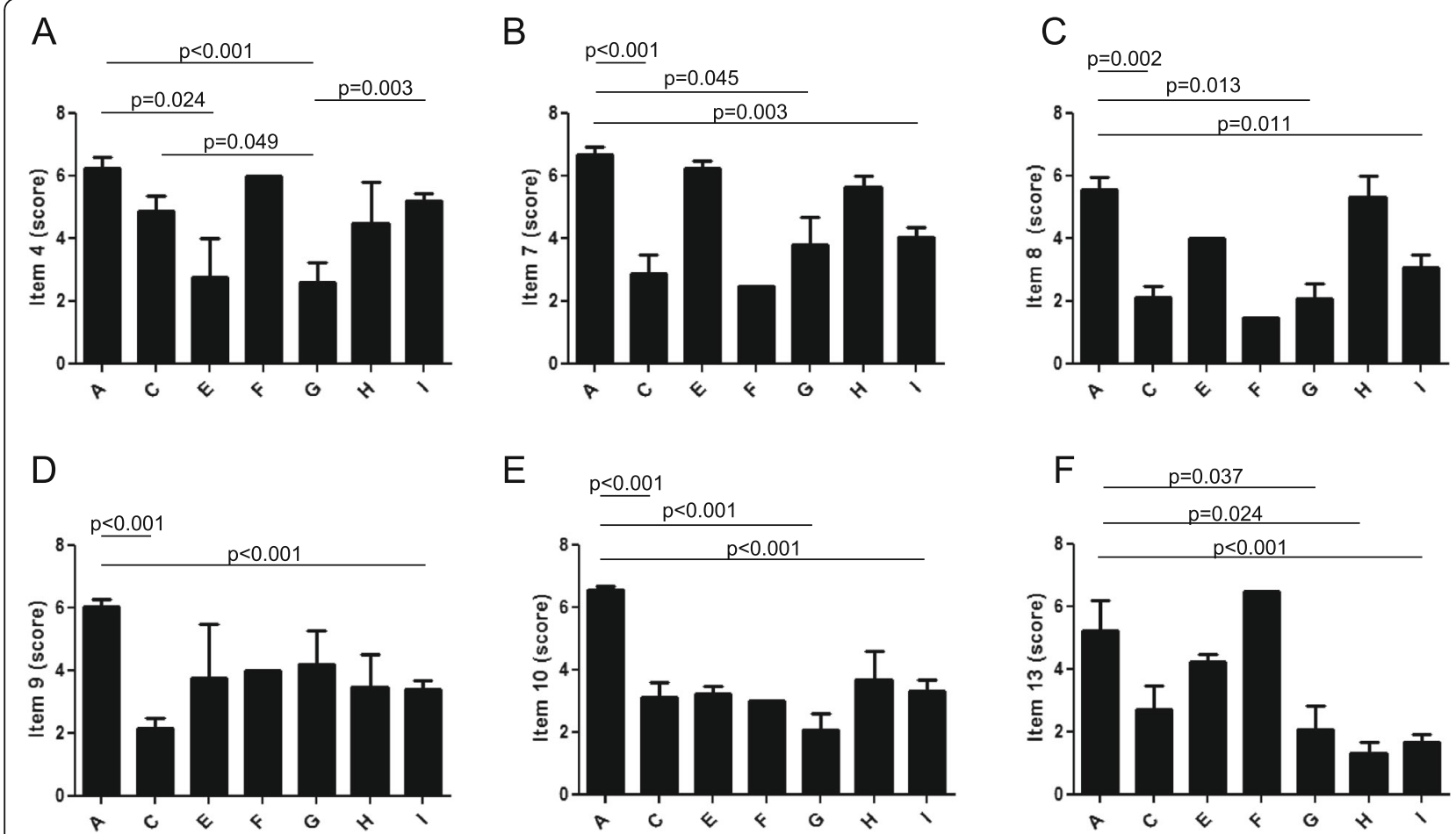

Fig. 7 Results of AGREE II appraisal for individual items. Scores obtained by the identified GLs and RCs on a 7-point scale for item 4 (a), item 7 (b), item $8(\mathbf{c})$, item $9(\mathbf{d})$, item $10(\mathbf{e})$ and item $13(\mathbf{f})$. Data are presented as mean \pm SD of values obtained by each group of disorders in each item. A: amino acid and organic acid metabolism $(n=8) ; \mathrm{C}$ : carbohydrate metabolism $(n=9)$; E: vitamin and non protein cofactor metabolism and transport $(n=2)$; G: mineral absorption and transport $(n=5)$; H: energy metabolism $(n=3)$; I: lysosomal and lysosomal-related organelles $(n=27)$

and transparency applied during GL development [15]. Thus, the performed analysis can be considered as a valuable tool for the elaboration of new GLs and RCs for iNMDs, since it provides methodological models for GL developers. On the other hand, it also offers a precise and updated picture about the existing GLs for iNMDs. This review could be useful for practical clinical purposes but also as an overview to detect what disorders do not currently have any official guide.

AGREE II scores indicate that the overall methodological quality of the GLs and RCs for selected iNMDs is acceptable (although very few of them obtained a score $\geq 50 \%$ in at least five items), and increasing over time. In addition, in all the appraised GLs and RCs the authors sufficiently describe the overall objectives, the covered health questions and the population whom they are directed.

Similarly, the appraisers judged that for most of the documents, the RCs were sufficiently specific, unambiguous, and easily identified, and that the different options for diagnosis or management were clearly presented. The availability of identifiable information facilitates the task of the health professionals when choosing the proper guidance.

We choose the year 2000 as lower limit for GL and RC search because we consider that from this year onwards experts in iNMDs have acquired more awareness about the necessity to provide guidance, as well as to collaborate and create networks. This may be due to the fact that in the last 15 years the number of patients who have been successfully diagnosed for iNMDs increased, also thanks to the availability of more precise and reliable diagnostic techniques. In this regard, we observed a substantial increase in the number of GLs and RCs for iNMDs, especially in the last few years.

Interestingly, only $23 \%$ of the 251 documents identified in the first search met the inclusion criteria and we often observed a widespread misuse of the term "guideline" that was utilized for systematic reviews, algorithms or letters. Indeed, until now the most common way of providing an overview or global knowledge about a particular disease or group of disorders in the field of iNMDs was by elaborating extensive systematic reviews of the published literature. The resultant documents were often used by health professionals as GLs or RCs. In the last years, the tendency changed and groups of experts meet with the exclusive purpose of writing well-structured evidencebased GLs [16, 17].

However, we could not find GLs and RCs for most of iNMDs, although disorders including Pompe disease, Gaucher disease, Fabry disease and MPSs were covered by at least three GLs or RCs. This disproportionate 


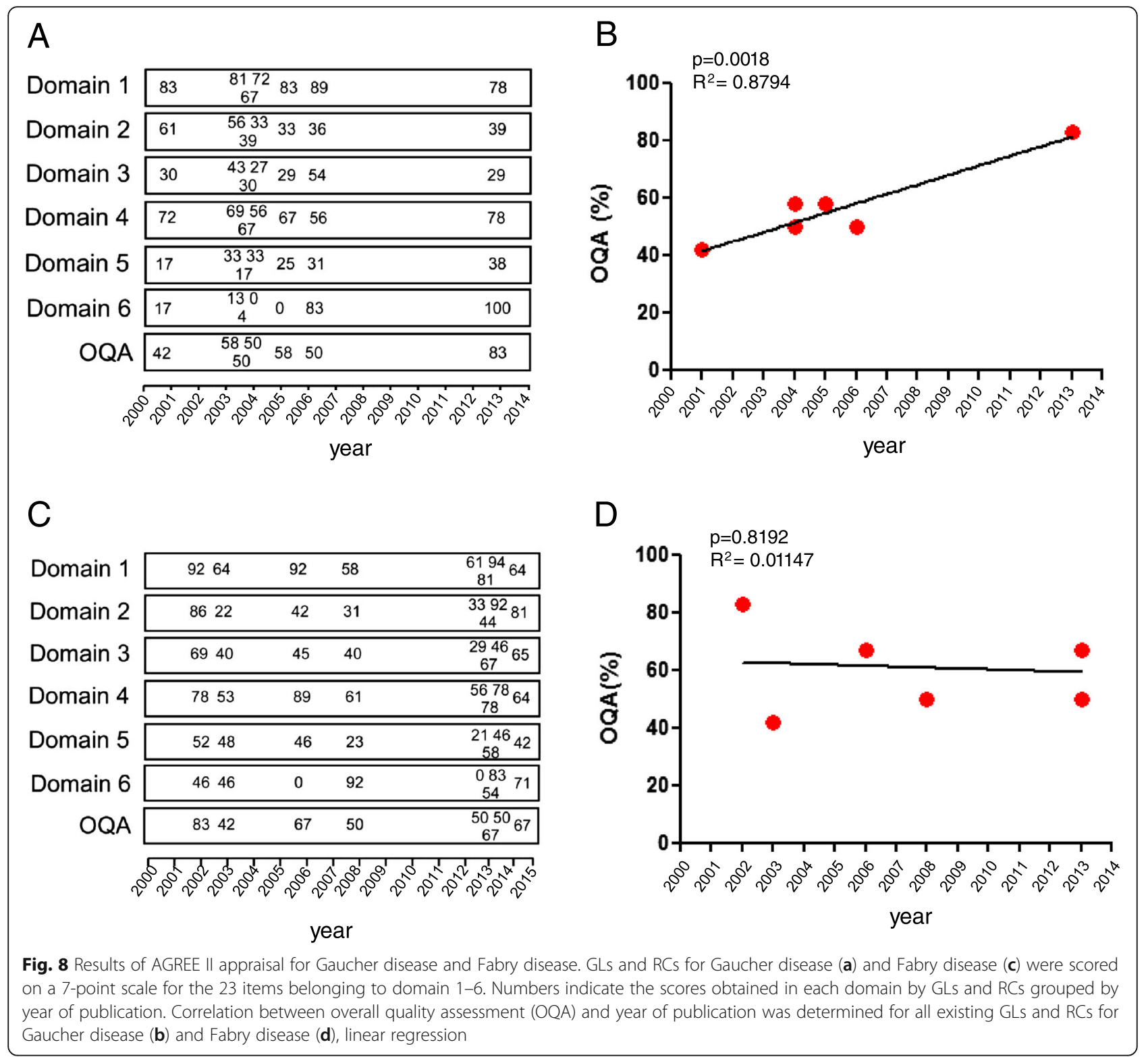

distribution of GLs and RCs could imply that guidance is prevalently provided for potentially treatable disorders, for which fully tested or still experimental therapies already exist. In this respect, we also observed that 50-100 \% of the GLs and RCs for Pompe disease, Gaucher disease, Fabry disease and MPSs were partially or totally funded by pharmaceutical companies, which may be particularly interested in the dissemination of RCs that promote the use of their own treatments. This observation may also entails that GL development is a costly process that may require external funding to be realized and may explain why most of the iNMDs still do not have guidance for their diagnosis or treatment.

On the other hand, it has to point out that often GLs and RCs not even exist for several treatable disorders, including different vitamin (thiamine, riboflavine, biotine, vitamin E)-responsive diseases, the glucose transporter type 1 (Glut1) deficiency, or the cerebrotendinous xanthomatosis (CXT), among others. In this case, lack of GLs could be ascribed to a still insufficient information about the phenotype and the progression of the disorder, or the correct treatment requirement.

However, two different European networks are currently working on the elaboration of GLs and RCs for treatable homocystinurias and neurotrasmitter defects (unpublished data).

The rarity of iNMDs may also explain the lack of available GLs for their screening, diagnosis, management or follow-up. In fact, few clinical trials exist and the 
published evidence often consists of isolated case reports and is not sufficient to elaborate a GL. Similarly, expert opinion is often inadequate in the case of ultra-rare disorders, because clinicians can see an individual condition only rarely in a career [18]. Nevertheless, the knowledge in the field of iNMDs has enormously increased in the last decades. Thus, the establishment of international networks composed by experts encompassing all the health specialties related to iNMD disorders could dramatically enhance the number of GLs for practice. In particular, more attention should be paid to disorders for which therapeutic possibilities already exist, in order to establish the bases for a proper treatment or follow-up of the patients.

Some recent GLs, such as those about urea cycle disorders (UCDs) or organic acidurias (OA) among others, have been created in the context of EuropeanInternational projects funded by the European Commission, where consortiums composed by many countries and expert centers were formed in order to elaborate specific plans for GL development [19, 20]. This strategy could explain why GLs and RCs covering disorders of amino acid and organic acid metabolism obtained the highest scores in almost all the domains. Indeed, our results show that although the correlation was not statistically significant, the overall quality of the GLs and RCs was higher when the number of authors or affiliations involved in its development increased.

The AGREE II analysis revealed that the elaboration of most of the selected GLs did not involve the target population (patients or public). This could be due to different factors, such as the difficulty to identify and recruit patients or representatives of the public or the discrepancy between the perspectives of expert and nonexpert members. In addition, the target population often does not have familiarity with the scientific and medical terminology [21]. Nonetheless, an effort should be done to increase the collaboration between experts and patients or public, by providing them with scientific support, training and mentoring. This could lead to more relevant and understandable GLs or to the production of additional material, such as quick reference guides or leaflets that could assist patients and families along the course of the disease.

Our data also showed that the majority of the GLs and RCs were published without an external review prior to submission for publication. The GL revision by one or more external experts working in the same subject area would likely improve the methodological quality of the recommendations. In fact, external reviewers coming from different countries or medical fields could provide a more comprehensive view about diagnosis or management options for iNMDs.
On the other hand, an expert external advice prior to the elaboration of the guidance would be certainly valuable, in order to ensure the adoption of the most rigorous and structured possible methodology.

We observed that $73 \%$ of the GLs and RCs did not provide a procedure for their updating, and some disorders were covered by only one document published several years ago $[22,23]$. On the other hand, four of the documents are revised version of previously published GLs and RCs [20, 24-26]. The updated version of previous GLs and RCs may present an improve in the OQA [24], or in the overall recommendation grade [20]. However, the small number of updated documents we identified with our search is not sufficient to determine whether the methodological quality of a guidance increases in its later versions. The updating of a GL should collect all the new evidence reported as well as information about the development of new technologies in diagnosis and treatment, thus reducing the variability among the documents published about the same disorders. However, very little information is available so far to indicate when a GL should be updated [27-29]. In this respect, we observed that the time between the first and the updated versions of the same GLs and RCs for iNMDs ranged between 3 and 9 years.

The frequency of iNMDs varies among different populations, and higher rate of consanguinity normally results in a significantly higher incidence of the disease. For example, the frequency of methilmalonic acidemia (MMA) is higher in Saudi Arabia, whereas glutaric aciduria type 1 (GA1) is more recurrent in the Old Order Amish in United States. This heterogeneous distribution of iNMD might imply that different strategies should be adopted by each country according to its possibilities. Indeed, because of the local economic conditions, some treatments, medical instruments or support infrastructure may be available in one country, but eventually not in another one [30, 31]. In this regard, none of the appraised documents referred to suitable alternatives for more vulnerable regions or countries, although an assessment of the implementation and adaptation of GLs for UCDs has been recently reported [31].

In addition, most of the analyzed documents did not consider neither the economical impact of applying the GL, probably because it may be difficult to predict costs and benefits, especially for long-term treatments [16]. Finally, none of the appraised GLs and RCs evaluated the risks versus benefits related to different social, economic or geographic realities.

This systematic search may present some limitations. First, we cannot exclude that we may have overlooked important GLs and RCs. Moreover, we only included documents in English, so GLs and RCs in other languages were not considered. Second, GLs were reviewed 
by two different appraisers and although a consensus was reached in case of discrepancy, they might have different level of understanding of the AGREE II instrument. In addition, since a reference cannot be provided by the AGREE II instrument, the perception that the appraiser had of the quality of a GL may have varied for each document and could be influenced by the comparison with the previous one.

\section{Conclusions}

Our analysis indicates that more documents are needed to encompass all the iNMDs that still lack guidance for their screening, diagnosis, treatment or follow-up. Considering AGREE II as a valuable tool for GL development, we observed that many of the existing GLs and RCs do not respond to the proposed criteria. In particular, new GL developers should take greater account of aspects that are still too overlooked. First of all, a GL should contain accurate information about how the evidence is searched, selected, validated and supporting the RC. Moreover, GL developers should consider the associated health benefits, side effects, and risks. In this regard, we also emphasize the necessity to externally review and update the GLs and to adapt them to the different social, economic and cultural realities. Finally, patients and society should be called to participate in the development of new RCs.

\section{Additional file}

Additional file 1: Table S1. Results of AGREE II appraisal for guidelines and recommendations for the most frequently covered iNMDs. (DOC $70 \mathrm{~kb}$ )

\section{Competing interests}

MS and AGC participated in the elaboration of some of the selected guidelines [20, 32-36], but were not involved in GL appraisal by AGREE II instrument.

\begin{abstract}
Authors' contributions
LC acquired, validated and analyzed the data, and drafted the manuscript. ECS participated in the design of the study, acquired and validated the data with AGREE II tool. MML validated the data with AGREE II tool and performed statistical analysis. DY, MJG, AO, CF, CJ, CS, ECP, FR, JA, MMOC $M C, R M$, and SMO validated the data with AGREE II tool. RA coordinated the validation process with AGREE II tool, validated the data and approved the final manuscript. IB, FBa, CMB, FBo, AC, LCS, CID, FD, KF, VG, CL and MS participated in the design of the study and approved the final manuscript. AGC supervised the research group, participated in the design of the study, contributed to the selection of quidelines and recommendations and to the interpretation of data, approved the final manuscript. All authors read and approved the final manuscript
\end{abstract}

\section{Acknowledgements}

This publication arises from the project InNerMeD-I-Network which has received funding from the European Union, in the framework of the Health Programme. Sole responsibility lies with the author and the Executive Agency is not responsible for any use that may be made of the information contained therein. We thank Silvia Semaan Llurba from the library service at Hospital Sant Joan de Déu for help in determining the best search strategy for PubMed database.

\section{Author details}

${ }^{1}$ Neurology, gastroenterology pathology and clinical biochemistry Departments, IRP-HSJD and CIBERER, Barcelona, Spain. ${ }^{2}$ Department of
Pediatrics, University Hospital Center Zagreb, Zagreb \& University of Zagreb, School of Medicine, Zagreb, Croatia. ${ }^{3}$ Gianni Benzi Pharmacological Research Foundation, Valenzano, BA, Italy. ${ }^{4}$ Department of Women and Children Health, Brains for Brain Foundation, Padova, Italy. ${ }^{5}$ Department of Clinical Genetics, Copenhagen University Hospital, Rigshospitalet, Copenhagen, Denmark. ${ }^{6}$ Department of Pediatric and Adolescent Medicine, Centre for Rare Diseases, Horst Schmidt Klinik Wiesbaden, Wiesbaden, Germany.

${ }^{7}$ Department of Women's and Children's Health, University of Padova, Padova, Italy.

Received: 12 August 2015 Accepted: 10 December 2015

Published online: 30 December 2015

\section{References}

1. Blau N, Duran M, Gibson KM, Dionisi-Vici C (Eds). Physician's Guide to the Diagnosis, Treatment, and Follow-Up of Inherited Metabolic Diseases. Springer-Verlag Berlin Heidelberg 2014.

2. Saudubray J-M, Georges van den B, Walter JH (Eds). Inborn Metabolic Diseases. Diagnosis and Treatment. 2012.

3. Poorthuis BJ, Wevers RA, Kleijer WJ, Groener JE, de Jong JG, van Weely S, et al. The frequency of lysosomal storage diseases in The Netherlands. Hum Genet. 1999:105:151-6.

4. Ahrens-Nicklas RC, Slap G, Ficicioglu C. Adolescent Presentations of Inborn Errors of Metabolism. J Adolesc Heal. 2015:56:477-82

5. Field MJ LK (Eds). Clinical Practice Guidelines: Directions for a New Program, Institute of Medicine. Washington, DC: National Academy Press; 1990

6. Lamari F, Mochel F, Saudubray J-M. An overview of inborn errors of complex lipid biosynthesis and remodelling. J Inherit Metab Dis. 2015:38:3-18.

7. Siering U, Eikermann M, Hausner E, Hoffmann-Eßer W, Neugebauer EA. Appraisal tools for clinical practice guidelines: a systematic review. PLoS One. 2013:8, e82915

8. Brouwers MC, Kho ME, Browman GP, Burgers JS, Cluzeau F, Feder G, et al. Development of the AGREE II, part 1: performance, usefulness and areas for improvement. CMAJ. 2010;182:1045-52.

9. Gagliardi AR, Brouwers MC. Do guidelines offer implementation advice to target users? A systematic review of guideline applicability. BMJ Open. 2015:5, e007047.

10. Birken SA, Ellis SD, Walker JS, DiMartino LD, Check DK, Gerstel AA, et al. Guidelines for the use of survivorship care plans: a systematic quality appraisal using the AGREE II instrument. Implement Sci. 2015;10:63.

11. Baris HN, Cohen IJ, Mistry PK. Gaucher disease: the metabolic defect, pathophysiology, phenotypes and natural history. Pediatr Endocrinol Rev. 2014;12 Suppl 1:72-81.

12. Zimran A, Elstein D. Management of Gaucher disease: enzyme replacement therapy. Pediatr Endocrinol Rev. 2014;12 Suppl 1:82-7.

13. El-Abassi R, Singhal D, England JD. Fabry's disease. J Neurol Sci. 2014:344:5-19.

14. Semlitsch T, Blank WA, Kopp IB, Siering U, Siebenhofer A. Evaluating Guidelines: A Review of Key Quality Criteria. Dtsch Arztebl Int. 2015:112:471-8.

15. The AGREE Collaboration. Development and validation of an international appraisal instrument for assessing the quality of clinical practice guidelines: the AGREE project. Qual Saf Health Care. 2003;12:18-23.

16. Eccles M, Mason J. How to develop cost-conscious guidelines. Health Technol Assess. 2001;5:1-69.

17. Camp KM, Parisi M, Acosta PB, Berry GT, Bilder D, Blau N, et al. Phenylketonuria scientific review conference: State of the science and future research needs. Mol Genet Metab. 2014;112:87-122.

18. Woolf S, Schünemann HJ, Eccles MP, Grimshaw JM, Shekelle P. Developing clinical practice guidelines: types of evidence and outcomes; values and economics, synthesis, grading, and presentation and deriving recommendations. Implement Sci. 2012;7:61.

19. Haeberle J, Boddaert N, Burlina A, Chakrapani A, Dixon M, Huemer M, et al. Suggested Guidelines for the Diagnosis and Management of Urea Cycle Disorders. Orphanet J Rare Dis. 2012;7:32.

20. Kölker S, Christensen E, Leonard JV, Greenberg CR, Boneh A, Burlina AB, et al. Diagnosis and management of glutaric aciduria type I - Revised recommendations. J Inherit Metab Dis. 2011;34:677-94.

21. Légaré F, Boivin A, van der Weijden T, Pakenham C, Burgers J, Légaré J, et al. Patient and public involvement in clinical practice guidelines: a knowledge synthesis of existing programs. Med Decis Making. 2011;31:E45-74.

22. Arnold GL, Koeberl DD, Matern D, Barshop B, Braverman N, Burton B, et al. A Delphi-based consensus clinical practice protocol for the diagnosis and 
management of 3-methylcrotonyl CoA carboxylase deficiency. Mol Genet Metab. 2008;93:363-70.

23. Angelini C, Federico A, Reichmann H, Lombes A, Chinnery P, Turnbull D. Task force guidelines handbook: EFNS guidelines on diagnosis and management of fatty acid mitochondrial disorders. Eur J Neurol. 2006;13:923-9.

24. Kaplan P, Baris H, De Meirleir L, Di Rocco M, El-Beshlawy A, Huemer M, et al. Revised recommendations for the management of Gaucher disease in children. Eur J Pediatr. 2013;172:447-58.

25. Patterson MC, Hendriksz CJ, Walterfang M, Sedel F, Vanier MT, Wijburg F. Recommendations for the diagnosis and management of Niemann-Pick disease type C: An update. Mol Genet Metab. 2012;106:330-44.

26. Weinreb NJ, Aggio MC, Andersson HC, Andria G, Charrow J, Clarke JTR, et al. Gaucher disease type 1: Revised recommendations on evaluations and monitoring for adult patients. Semin Hematol. 2004;41 Suppl 5:15-22.

27. Vernooij RWM, Sanabria AJ, Solà I, Alonso-Coello P, Martínez García L. Guidance for updating clinical practice guidelines: a systematic review of methodological handbooks. Implement Sci. 2014;9:3.

28. Shekelle P, Eccles MP, Grimshaw JM, Woolf SH. When should clinical guidelines be updated? BMJ. 2001;323:155-7.

29. Clark E, Donovan EF, Schoettker P. From outdated to updated, keeping clinical guidelines valid. Int J Qual Health Care. 2006;18:165-6.

30. Therrell BL, Padilla CD, Loeber JG, Kneisser I, Saadallah A, Borrajo GJC, et al. Current status of newborn screening worldwide: 2015. Semin Perinatol. 2015;39:171-87.

31. Häberle J, Huemer M. Evaluation of Implementation, Adaptation and Use of the Recently Proposed Urea Cycle Disorders Guidelines. JIMD Rep. 2015;21:65-70.

32. De Ru MH, Teunissen QG, van der Lee JH, Beck M, Bodamer O, Clarke L, et al. Capturing phenotypic heterogeneity in MPS I: results of an international consensus procedure. Orphanet J Rare Dis. 2012;7:22.

33. Wraith JE, Scarpa M, Beck M, Bodamer O, De Meirleir L, Guffon N, et al. Mucopolysaccharidosis type II (Hunter syndrome): A clinical review and recommendations for treatment in the era of enzyme replacement therapy. Eur J Pediatr. 2008;167:267-77.

34. Scarpa M, Almássy Z, Beck M, Bodamer O, Bruce I, De Meirleir L, et al. Mucopolysaccharidosis type II: European recommendations for the diagnosis and multidisciplinary management of a rare disease. Orphanet J Rare Dis. 2011;6:72

35. Muenzer J, Bodamer O, Burton B, Clarke L, Frenking GS, Giugliani R, et al. The role of enzyme replacement therapy in severe Hunter syndrome-an expert panel consensus. Eur J Pediatr. 2012;171:181-8.

36. Langereis EJ, Borgo A, Crushell E, Harmatz PR, van Hasselt PM, Jones $\mathrm{S}$, et al. Treatment of hip dysplasia in patients with mucopolysaccharidosis type I after hematopoietic stem cell transplantation: results of an international consensus procedure. Orphanet J Rare Dis. 2013;8:155.

37. Baumgartner MR, Hörster F, Dionisi-Vici C, Haliloglu G, Karall D, Chapman K, et al. Proposed guidelines for the diagnosis and management of methylmalonic and propionic acidemia. Orphanet J Rare Dis. 2014;9:130.

38. Frazier DM, Allgeier C, Homer C, Marriage BJ, Ogata B, Rohr F, et al. Nutrition management guideline for maple syrup urine disease: An evidenceand consensus-based approach. Mol Genet Metab. 2014;112:210-7.

39. Kölker S, Christensen E, Leonard JV, Greenberg CR, Burlina B, Burlina P, et al. Guideline for the diagnosis and management of glutaryl-CoA dehydrogenase deficiency (glutaric aciduria type I). J Inherit Metab Dis. 2007;30:5-22.

40. National Institutes of Health Consensus Development Panel. National Institutes of Health Consensus Development Conference Statement: phenylketonuria: screening and management, October 16-18, 2000. Pediatrics. 2001;108:972-82.

41. Vockley J, Andersson HC, Antshel KM, Braverman NE, Burton BK, Frazier DM, et al. Phenylalanine hydroxylase deficiency: diagnosis and management guideline. Genet Med. 2014;16:188-200.

42. Barba-Romero M, Barrot E, Bautista-Lorite J, Gutierrez-Rivas E, Illa I, Jimenez LM, et al. Clinical guidelines for late-onset Pompe disease. Rev Neurol. 2012; 54:497-507.

43. Cochat P, Hulton S-A, Acquaviva C, Danpure CJ, Daudon M, De Marchi M, et al. Primary hyperoxaluria Type 1: indications for screening and guidance for diagnosis and treatment. Nephrol Dial Transplant. 2012;27:1729-36.

44. Cupler EJ, Berger KI, Leshner RT, Wolfe GI, Han JJ, Barohn RJ, et al. Consensus treatment recommendations for late-onset Pompe disease. Muscle Nerve. 2012;45:319-33.

45. Kishnani PS, Austin SL, Abdenur JE, Arn P, Bali DS, Boney A, et al. Diagnosis and management of glycogen storage disease type $I$ : a practice guideline of the American College of Medical Genetics and Genomics. Genet Med. 2014(August):1-29.
46. Kishnani PS, Austin SL, Arn P, Bali DS, Boney A, Case LE, et al. Glycogen storage disease type III diagnosis and management guidelines. Genet Med. 2010;12:446-63.

47. Kishnani PS, Steiner RD, Bali D, Berger K, Byrne BJ, Case LE, et al. Pompe disease diagnosis and management guideline. Genet Med. 2006;8:267-88.

48. Rake JP, Visser G, Labrune P, Leonard JV, Ullrich K, Smit GP. Guidelines for management of glycogen storage disease type I - European Study on Glycogen Storage Disease Type I (ESGSD I). Eur J Pediatr. 1999;2002(161 Suppl):S112-9.

49. Visser G, Rake JP, Labrune P, Leonard JV, Moses S, Ullrich K, et al. Consensus guidelines for management of glycogen storage disease type $1 \mathrm{~b}$ European Study on Glycogen Storage Disease Type 1. Eur J Pediatr. 2002;161 Suppl:S120-3.

50. Winchester B, Bali D, Bodamer O, Caillaud C, Christensen E, Cooper A, et al. Methods for a prompt and reliable laboratory diagnosis of Pompe disease: Report from an international consensus meeting. Mol Genet Metab. 2008;93:275-81.

51. British Columbia Medical Services Commission. Cobalamin (vitamn B12) deficiency- INvestigation and management. 2011, NGC-9460.

52. Devalia V, Hamilton MS, Molloy AM. Guidelines for the diagnosis and treatment of cobalamin and folate disorders. Br J Haematol. 2014;166:496-513

53. Stein P, Badminton M, Barth J, Rees D, Stewart MF. Guidelines Article Best practice guidelines on clinical management of acute attacks of porphyria and their complications. Ann Clin Biochem. 2013;50(Pt 3):217-23.

54. Bacon BR, Adams PC, Kowdley KV, Powell LW, Tavill AS. Diagnosis and management of hemochromatosis: 2011 Practice Guideline by the American Association for the Study of Liver Diseases. Hepatology. 2011;2011 (54):328-43.

55. British Columbia Medical Association. HFE-Associated Hereditary Hemochromatosis Investigations and Management. 2013.

56. European Association for Study of Liver. EASL Clinical Practice Guidelines: Wilson's disease (European association or the study of the liver. J Hepatol. 2012;56:671-85.

57. Qaseem A, Aronson M, Fitterman N, Snow V, Weiss KB. Annals of Internal Medicine Clinical Guidelines Screening for Hereditary Hemochromatosis: A Clinical Practice Guideline from the American College of Physicians. 2005;517-22.

58. Roberts E, Schilsky ML. A practice guideline on Wilson disease. Hepatology. 2003;37:1475-92.

59. Arnold GL, Van Hove J, Freedenberg D, Strauss A, Longo N, Burton B, et al. A Delphi clinical practice protocol for the management of very long chain acyl-CoA dehydrogenase deficiency. Mol Genet Metab. 2009;96:85-90.

60. Finsterer J, Harbo HF, Baets J, Van Broeckhoven C, Di Donato S, Fontaine B, et al. EFNS guidelines on the molecular diagnosis of mitochondrial disorders. Eur J Neurol. 2009;16:1255-64.

61. Andersson HC, Charrow J, Kaplan P, Mistry P, Pastores GM, Prakash-Cheng A, et al. Individualization of long-term enzyme replacement therapy for Gaucher disease. Genet Med. 2005;7:105-10.

62. Bennett RL, Hart KA, O'Rourke E, Barranger JA, Johnson J, MacDermot KD, et al. Fabry Disease in Genetic Counseling Practice: Recommendations of the National Society of Genetic Counselors. J Genet Couns. 2002;1 1:121-46

63. Biegstraaten M, Arngrímsson R, Barbey F, Boks L, Cecchi F, Deegan PB, et al. Recommendations for initiation and cessation of enzyme replacement therapy in patients with Fabry disease: the European Fabry Working Group consensus document. Orphanet J Rare Dis. 2015; 10.

64. Charrow J, Andersson HC, Kaplan P, Kolodny EH, Mistry P, Pastores G, et al. Enzyme replacement therapy and monitoring for children with type 1 Gaucher disease: consensus recommendations. J Pediatr. 2004;144:112-20.

65. De Ru MH, Boelens JJ, Das AM, Jones S, van der Lee JH, Mahlaoui N, et al. Enzyme replacement therapy and/or hematopoietic stem cell transplantation at diagnosis in patients with mucopolysaccharidosis type l: results of a European consensus procedure. Orphanet J Rare Dis. 2011;6:55.

66. Desnick RJ, Brady R, Barranger J, Collins AJ, Germain DP, Goldman M, et al. Fabry disease, an under-recognized multisystemic disorder: expert recommendations for diagnosis, management, and enzyme replacement therapy. Ann Intern Med. 2003;138:338-46.

67. Eng CM, Germain DP, Banikazemi M, Warnock DG, Wanner C, Hopkin RJ et al. Fabry disease: guidelines for the evaluation and management of multi-organ system involvement. Genet Med. 2006;8:539-48.

68. Fahnehjelm KT, Ashworth JL, Pitz S, Olsson M, Törnquist AL, Lindahl P, et al. Clinical guidelines for diagnosing and managing ocular manifestations in children with mucopolysaccharidosis. Acta Ophthalmol. 2012;90:595-602. 
69. Giugliani R, Harmatz P, Wraith JE. Management guidelines for mucopolysaccharidosis VI. Pediatrics. 2007;120:405-18.

70. Grabowski GA, Andria G, Baldellou A, Campbell PE, Charrow J, Cohen IJ, et al. Pediatric non-neuronopathic Gaucher disease: Presentation, diagnosis and assessment. Consensus statements. Eur J Pediatr 2004, 163:58-66.

71. Kes VB, Cesarik M, Zavoreo I, Soldo-Butković S, Kes P, Basić-Jukić N, et al. Guidelines for diagnosis, therapy and follow up of Anderson-Fabry disease. Acta Clin Croat. 2013;52:395-405.

72. Laney D, Bennett RL, Clarke V, Fox A, Hopkin RJ, Johnson J, et al. Fabry disease practice guidelines: Recommendations of the national society of genetic counselors. J Genet Couns. 2013;22:555-64.

73. Muenzer J, Wraith JE, Clarke L. Mucopolysaccharidosis I: management and treatment quidelines. Pediatrics. 2009:123:19-29.

74. Ortiz A, Oliveira JP, Wanner C, Brenner BM, Waldek S, Warnock DG Recommendations and guidelines for the diagnosis and treatment of Fabry nephropathy in adults. Nat Clin Pract Nephrol. 2008;4:327-36.

75. Peters C, Steward CG. Hematopoietic cell transplantation for inherited metabolic diseases: an overview of outcomes and practice guidelines. Bone Marrow Transplant. 2003;31:229-39.

76. Solanki G, Alden TD, Burton BK, Giugliani R, Horovitz DDG, Jones S, et al. A multinational, multidisciplinary consensus for the diagnosis and management of spinal cord compression among patients with mucopolysaccharidosis VI. Mol Genet Metab. 2012;107:15-24.

77. Terryn W, Cochat P, Froissart R, Ortiz A, Pirson Y, Poppe B, et al. Fabry nephropathy: Indications for screening and guidance for diagnosis and treatment by the European Renal Best Practice. Nephrol Dial Transplant. 2013;28:505-17.

78. Vellodi A, Bembi B, De Villemeur TB, Collin-Histed T, Erikson A, Mengel E, et al. Management of neuronopathic Gaucher disease: A European consensus. J Inherit Metab Dis. 2001;24:319-27.

79. Vom Dahl S, Poll L, Di Rocco M, Ciana G, Denes C, Mariani G, et al. Evidence-based recommendations for monitoring bone disease and the response to enzyme replacement therapy in Gaucher patients. Curr Med Res Opin. 2006;22:1045-64.

80. Wang RY, Bodamer O, Watson MS, Wilcox WR. Lysosomal storage diseases: diagnostic confirmation and management of presymptomatic individuals. Genet Med. 2011:13:457-84.

81. Wraith JE, Baumgartner MR, Bembi B, Covanis A, Levade T, Mengel E, et al. Recommendations on the diagnosis and management of Niemann-Pick disease type C. Mol Genet Metab. 2009;98:152-65.

\section{Submit your next manuscript to BioMed Central and we will help you at every step:}

- We accept pre-submission inquiries

- Our selector tool helps you to find the most relevant journal

- We provide round the clock customer support

- Convenient online submission

- Thorough peer review

- Inclusion in PubMed and all major indexing services

- Maximum visibility for your research

Submit your manuscript at www.biomedcentral.com/submit

) Biomed Central 